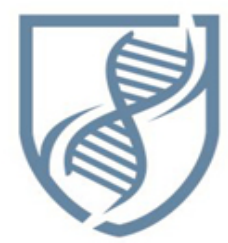

Journal of Bioscience and Applied Research

\section{JBAAR}

WWW.JBAAR.ORG

\title{
Effect of metformin on histopathological and immunohistochemical changes induced by high fructose intake in liver and brain of rats
}

\author{
Eman Ahmed Youssef \\ Histochemistry and Cell Biology Department \\ Medical Research Institute, Alexandria University, Egypt \\ (Corresponding author email: eman_khalifa_124@yahoo.com)
}

\begin{abstract}
Fructose is widely used as a food ingredient and has the potential to increase oxidative stress and related complications. The present study was designed to evaluate the role of metformin on histopathological and immunohistochemical changes in liver and brain of rat induced by high fructose intake. Forty male albino rats were divided into 4 groups. Groups I and II served as controls. Group III received $10 \%$ drinking fructose solution for eight weeks. Group IV was received $10 \%$ drinking fructose solution for eight weeks and treated with metformin (320 mg/kg/day) during the last 4 weeks of the experimental period. Rats were sacrificed after 8 weeks; liver and brain were excised and fixed in $10 \%$ neutral buffered formalin. Histopathological results: Fructose drinking manifested changes in liver and brain cerebral cortex. Liver changes were manifested as inflammation, apoptosis, dilated sinusoids, fibrosis, macrosteatosis, ballooned hepatocytes and marked collagen deposition, while brain changes were degenerating neurons, steatosis, karyorrhexis, and pyknotic nuclei in nuropil and lightly stained Nissl substance with cresyl violet. Metformin treatment eliminated histopathological changes in addition to decreased collagen deposition in liver and improved Nissl substance staining in brain. Immunohistochemical results showed increased immunostaining positivity of caspase-3 and inducible nitric oxide synthase ( iNOS) in liver and brain in fructose group . Reduced immunoreactivity of caspase-3 and iNOS in fructose plus metformin group either in liver or brain sections. In conclusion, the results suggest that the hepatoprotective and neuroprotective role of metformin on histopathological and
\end{abstract}

and immunohistochemical changes induced by fructose could be attributed to its ability to reduce oxidative stress.

Keywords: Fructose, metformin, liver, brain, histopathology, caspase-3, iNOS,

\section{Introduction}

Increased fructose consumption has deleterious effects associated with metabolic syndrome; impaired glucose tolerance, insulin resistance (IR), hyperlipidemia, oxidative stress and endothelial dysfunction. (Rayssiguier et al, 2006, Stanhope and Havel, 2008 \& 2009 and Altas et al, 2010). Exposure of the liver to such large quantities of fructose leads to rapid stimulation of lipogenesis and triglyceride accumulation, which in turn contributes to reduced insulin sensitivity and hepatic insulin resistance/glucose intolerance (Basciano et al, 2005). Many authors in their studies on rodents demonstrated various histological alterations of liver tissue after fructose consumption (Ackerman et al, 2005, Armutcu et al, 2005 and Sanchez-Lozada, et al, 2010) and induced fatty liver as indicated by Ouyang et al. (2008).

In rodents, the intake of large quantities of fructosecontaining food and drinks or high-fructose corn syrup (HFCS) induced IR (Morino et al. 2006). IR is the pivotal causative mechanism of type II diabetes, hypertension and cardiovascular diseases (Reddy et al, 2010 and Kim \& Feldman, 2012). Insulin resistances in the CNS are widely expressed throughout the brain in neurons and glial cells, at particularly high concentrations in the cerebral cortex, hippocampus, hypothalamus, and olfactory bulb (Neumann et al., 2008). IR leads to greater oxidative stress, DNA damage, mitochondrial dysfunction, and, ultimately, cell 
death (de la Monte, 2009) considering that oxidative stress impaired insulin action (Paolisso et al, 1996).

Fructose overload has been shown to increase oxidative stress. Delbosc et al (2005) found that high fructose feeding was associated with increase in reactive oxygen species (ROS) production. Several studies have shown that the administration of high fat or high calorie diets to rodents can specifically increase free radical generation (Zhang et al, 2005 ) and protein oxidation (Souza et al , 2007) in the brain.

It has been reported that neurons in hyperglycemic environment displayed signs of apoptosis due to hyperglycemia-induced oxidative stress (Edwards et al, 2008).

Caspase- 3 is the executioner caspase known to play a central role in the proteolytic cascade during apoptosis. (Earnshaw et al, 1999, and Wolf et al, 1999). The detection of activated caspase-3 is a very reliable way to identify cells destined to die by apoptosis, even before many of the morphologic characteristics (e.g., DNA fragmentation) are present. (Stadelmann and Lassmann, 2000).

The inducible isoform, iNOS is expressed in several cell types including macrophages (Lyons et al., 1992), hepatocytes, (Geller et al., 1993) and vascular smooth muscle cells (Nakayama et al., 1992) in response to cytokines. iNOS plays an important role in vascular smooth muscle dilation as well as inflammatory response (Wei et al., 1995). In the liver of diabetic rats , an increase of TNF$\alpha$ was found due to increased expression of iNOS which led to a high production of NO (Ingaramo et al, 2011). Similar results have been reported in different tissues by other authors ( Powell et al, 2004 and Stadler et al, 2008). It was well-established that excessive nitric oxide production via iNOS plays a fundamental role in neuronal cell damage (Wei et al, 2000 and Bal-Price and Brown, 2001).

Metformin, a drug widely used in the treatment of type 2 diabetes through inhibiting the formation of hepatic fibrosis (Qiang et al, 2010). It is described as an efficient treatment for nonalcoholic steatohepatitis (NASH) and hepatic inflammation (Kita et al, 2012) and protects against fructose-induced liver steatosis (Spruss et al 2012). Metformin affects cerebral metabolism in some white matter and semantic memory related sites in patients with type 2 diabetes ( Huang, et al, 2014) and it is a neuroprotective in alloxan-induced diabetic rats ((Akinola et al, 2012). The aim of this study was to clarify the effective role of metformin on histopathological changes in liver and brain of rat induced by high fructose intake and its correlation with immunohistochemical expression of iNOS and caspase 3 .

\section{Materials and Methods}

The present study was carried out on forty adult male albino rats, weighing $100-120 \mathrm{~g}$, were obtained from the Laboratory Animal Unit, Medical Research Institute, Alexandria University. Rats were kept under the same laboratory conditions of $20-25{ }^{0} \mathrm{C}$ and $12 \mathrm{~h}$ light-dark cycle and received a standard food and water ad libitum. Animals were handled in accordance with the protocol of
Laboratory Animal Unit of Medical Research Institute, Alexandria University concerning with guiding principles for biomedical research involving animals. After one week of adaptation, rats were randomly divided into four groups each of 10 rats.

Group I: Normal control rats were received standard diet and water ad libitum.

Group II: Experimental control rats were received control diet and water ad libitum for eight weeks and administered metformin (Minapharm Pharmaceutical Co., Egypt) orally in a dose of $320 \mathrm{mg} / \mathrm{kg} /$ day (Rouru et al, 1992) by gastric tube during the last 4 weeks of the experimental period.

Group III: Rats were received control diet and $10 \%$ drinking fructose solution (EL Nasr Pharmaceutical Chemicals Co., Egypt) for eight weeks.

Group IV: Rats were received $10 \%$ drinking fructose solution for eight weeks and treated with metformin (320 $\mathrm{mg} / \mathrm{kg} /$ day) during the last 4 weeks of the experimental period.

At the end of experiment, rats of all groups were sacrificed under anesthesia; liver and brain were immediately excised and fixed in $10 \%$ neutral buffered formalin. Paraffin sections from liver tissue as well as from cerebral cortex of brain were prepared to perform the following studies:

\section{Histopathological studies:}

a. Sections , $4 \mu$ thick, from liver and cerebral cortex of brain were processed for routinely staining with haematoxylin and eosin (H\&E) to examine the histopathological changes (Bancroft and Stevens, 2002)

b. Masson trichrome stain for collagen: $4 \mu$ thick liver sections were rehydrated, mordant in Bouin's fixative, washed in running tap water to remove picric acid color and stained with Weigert's hematoxylin. Then, sections were stained in Biebrich scarlet-acid fuchsin solution, differentiated in phosphomolybdicphosphotungstic acid solutions, then lastly stained with fast green FCF and processed to be mounted (Suvik and Effendy, 2012).

c. Cresyl violet for Nissl substance: Paraffin brain sections at $6 \mu \mathrm{m}$ thick were stained with $0.5 \%$ aqueous solution of cresyl violet according to the method of Luna (1968).

\section{Immunohistochemical study:}

Immunohistochemical staining of caspase 3 and inducible nitric oxide synthase (iNOS) in liver and brain sections were performed according to the manufacturer's manual in the following procedure:

Sections at $4-\mu \mathrm{m}$ thickness were brood onto coated glass slides, deparaffinized in xylene, rehydrated and rinsed in phosphate buffered saline (PBS). Sections were incubated in $3 \% \mathrm{H}_{2} \mathrm{O}_{2}$ in methanol for 10 minutes to inhibit endogenous peroxidase activity, and blocked with nonspecific staining blocking reagent. Sections were incubated overnight at $4{ }^{0} \mathrm{C}$ with the antibodies against caspase-3 (rabbit polyclonal antibody at dilution 1:200, Thermo Scientific, Ab-4) and iNOS (rabbit polyclonal 
antibody at dilution 1:100, ab15323). Sections were then processed using a secondary antibody streptavidin biotin peroxidase complex kit (Sigma Co). The immunohistochemical reaction was then developed and stained with diaminobenzidine chromogen solution "DAB" (Sigma). The sections were counterstained with hematoxylin, dehydrated, cleared, and mounted with DPX. For the negative controls, PBS was used in place of the primary antibody.

\section{Image analysis:}

Digital images were analyzed by a semi-quantitative scoring system (Image J software, Java based application for analyzing images).

Violet stained area of Nissl substance in brain sections and the blue to green stained collagen areas in liver sections were analyzed; the percentage colored stained area (area fraction) per field area was determined by measuring five randomly photographed high-power fields (x400 magnifications) by a blinded observer. The brown stained immunohistochemical expressions of caspase 3- positive cells were analyzed by two ways; either by counting the numbers of positive staining cells or by measuring the percentage colored stained area per field area in five randomly high power fields at magnification of $x 400$. The immunostaining reaction of iNOS positive cells was analyzed by measuring percentage area.

\section{Statistical analysis of the data}

Data which obtained by image analysis was analyzed using IBM SPSS software package version 20.0. ANOVA was used to compare the four studied groups for normally distributed quantitative variables, while Post Hoc Test (Tukey) was used to pair wise between different studied groups. Kruskal Wallis test was used to compare different groups for abnormally distributed quantitative variables and Mann Whitney test was used for comparing each two groups. Significance of the obtained results was judged at the $5 \%$ level.

\section{Results}

\section{Histopathological Results:}

\section{Histopathological changes in Liver:}

Control normal liver sections stained with H\&E revealed normal hepatocytes arranged in plates radiating from central vein; with patent hepatic sinusoids and Kupffer cells were associated with sinusoidal lining cells (Figure 1A). Liver sections of metformin treated rats exhibited normal histological structure with little number of hepatocytes having apoptotic figures (Figure 1B). Liver sections of fructose drinking rat revealed inflammatory cellular infiltration around congested central vein, pericentral increased numbers of apoptotic figures and dilated sinusoids (Figure 2). Lymphocytic periportal infiltration, fibrosis and macrosteatosis displayed hepatocytes with ballooned clear cytoplasm as well as many apoptotic figures were also observed (Figure 3 A\&B). Examined liver sections of fructose drinking rats treated with metformin showed almost normal hepatocytes around central vein with patent sinusoids and minimal number of apoptotic figures (Figure $4 \mathrm{~A}$ ). Decreased inflammatory cellular infiltration in portal area, minute number of hepatocytes with apoptotic or necrotic figures was also seen. (Figure $4 \mathrm{~B}$ ).

Liver sections stained with Masson's trichrome stain revealed thin blue rims of collagen around central vein and demarcated the sinusoids in control rats and those treated with metformin (Figure 5 A\&B). Liver sections of fructose drinking rat showed marked collagen deposition in portal area denoted presence of fibrosis (Figure 6). Weak collagen deposition was observed in liver sections of fructose drinking rats treated with metformin (Figure 7).

The mean percentage area of collagen deposition stained with Masson's trichrome stain in liver sections was expressed in mean $\pm \mathrm{SD}$ and was compared using $\mathrm{F}$ test (ANOVA). Fructose group (8.04 \pm 1.53$)$ and fructose treated metformin group $(4.93 \pm 0.80)$ showed higher significant difference $(\mathrm{p}<0.001)$ as compared with control group $(2.01 \pm 0.91)$ and metformin treated group (2.54 \pm 0.96). Moreover, fructose treated metformin (4.93 \pm 0.80$)$ displayed lower significant $(<0.001)$ comparing with fructose group (8.04 \pm 1.53$)$.

\section{Histopathological changes in Brain:}

Brain sections of control rats stained with $\mathrm{H} \& \mathrm{E}$ showed cerebral cortex included pyramidal cells with apical dendrites, neuronal and glial cell bodies are embedded in neuropil (Figures 8). Brain cortex of metformin treated rat showing more or less normal architecture of cerebral cortex with neuronal cell body, glial cell body and neuropil (Figure 9). Fructose consumption for 8 weeks enhanced severe histopathological changes in rat brain. Increased degenerating neurons with eosinophilic cytoplasm, swelling and vacuolation in neuronal cell bodies, increased steatosis in nuropil, karyorrhectic and pyknotic nuclei were observed in cerebral cortex (Figure 10). Treatment with metformin plus fructose drinking revealed enhancement of normal form of neuronal cell and glial cell bodies and blood vessels in neuropil of brain cortex in addition to diminished steatosis (Figure 11).

Cresyl violet stain was used to stain Nissl substance in the cytoplasm of neurons in violet color. Cerebral cortex in rats of control and those treated with metformin revealed normal histoarchitecture of neurons with round neuronal cell body and cytoplasm with strongly stained Nissl substance (Figure 12A \&B) . Brain sections stained with cresyl violet staining depicted lightly stained reduced Nissl substance in cerebral cortex in rats that have drunken fructose for 8 weeks (Figure 13 A). Cerebral cortex of rats treated metformin with fructose consumption revealed Nissl substance in neuronal cell body in moderate staining as compared with control brain sections (Figure $13 \mathrm{~B}$ ). 


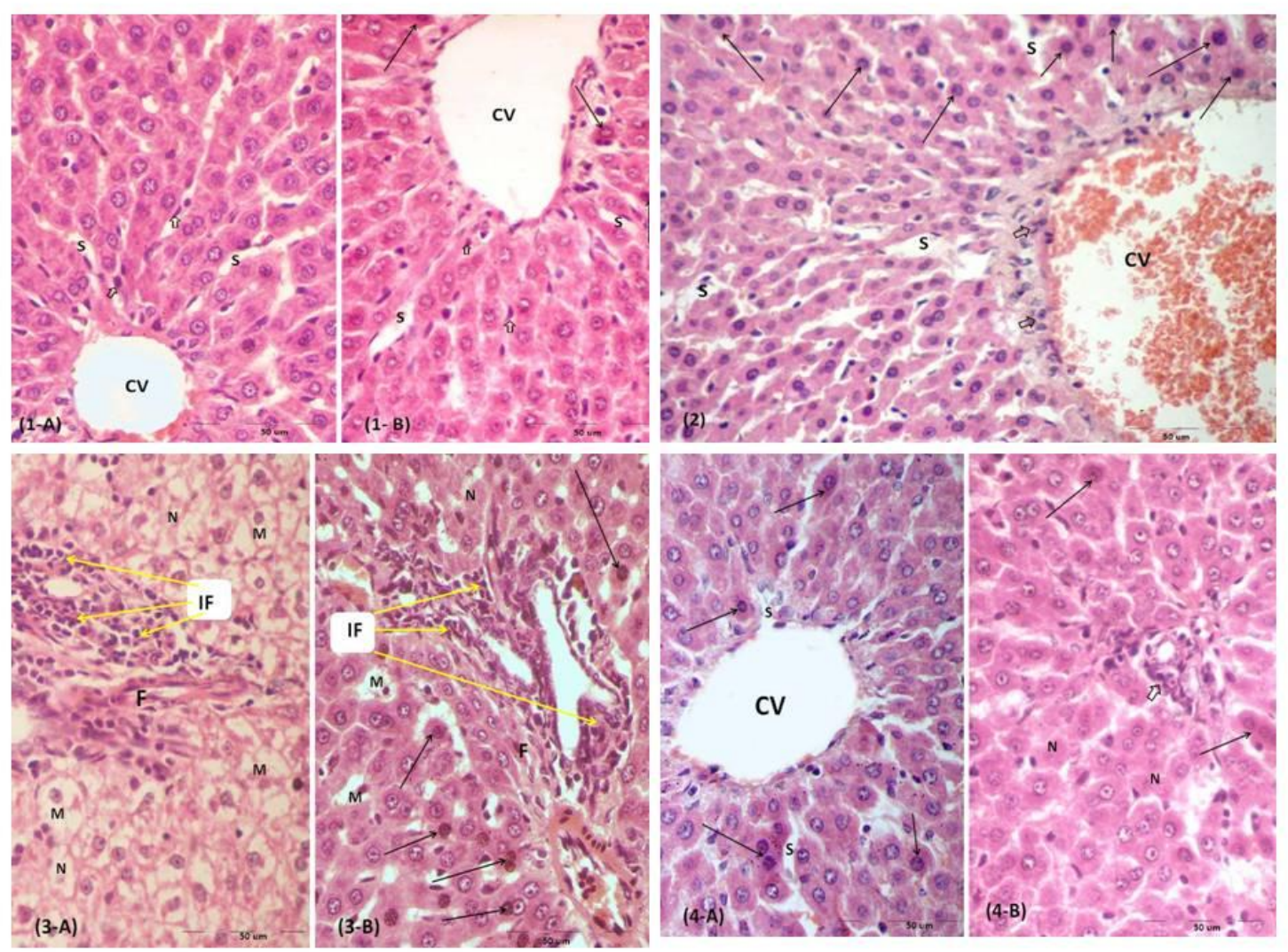

Figure (1): Photomicrographs of liver sections stained with H\&E showing: [A] hepatocytes arranged in branching and anastomosing cords radiating from the central veins (CV), sinusoids (S) and Kupffer cells ( $\uparrow$ ) in control rats. [B] More or less normal hepatocytes architecture with little number of hepatocytes having apoptotic figures $(\uparrow)$ in rat liver section treated with metformin. (Bar=50 $\mu \mathrm{m}$ ).

Figure (2): A Photomicrograph of liver section of fructose drinking rat showing inflammatory cellular infiltration (仓) around congested central vein (CV) impacted with haemolysed blood, peri-central increased numbers of apoptotic figures ( $\uparrow$ ) and dilated sinusoids (S). (H \& E; Bar=50 $\mu \mathrm{m})$.

Figure (3): Photomicrographs of liver sections of fructose drinking rats [A and B]; showing inflammatory cells (IF), fibrosis (F), increased area with macrosteatosis (M); where hepatocytes have ballooned clear cytoplasm in portal triad area. Note: Necrosis $(\mathrm{N})$ and many apoptotic figures $(\uparrow)$. (H \& E; Bar=50 um).

Figure (4): Photomicrographs of liver sections of fructose drinking rats treated with metformin showing: [A] Plates of almost normal hepatocytes around central vein (CV), sinusoids (S), and minimal number of apoptotic figures ( $\uparrow$ ). [B] Decreased inflammatory cellular infiltration in portal area (仓), minute number of hepatocytes with apoptotic ( $\uparrow$ ) or necrotic (N) figures. (H \& E; Bar=50 $\mu \mathrm{m})$. 


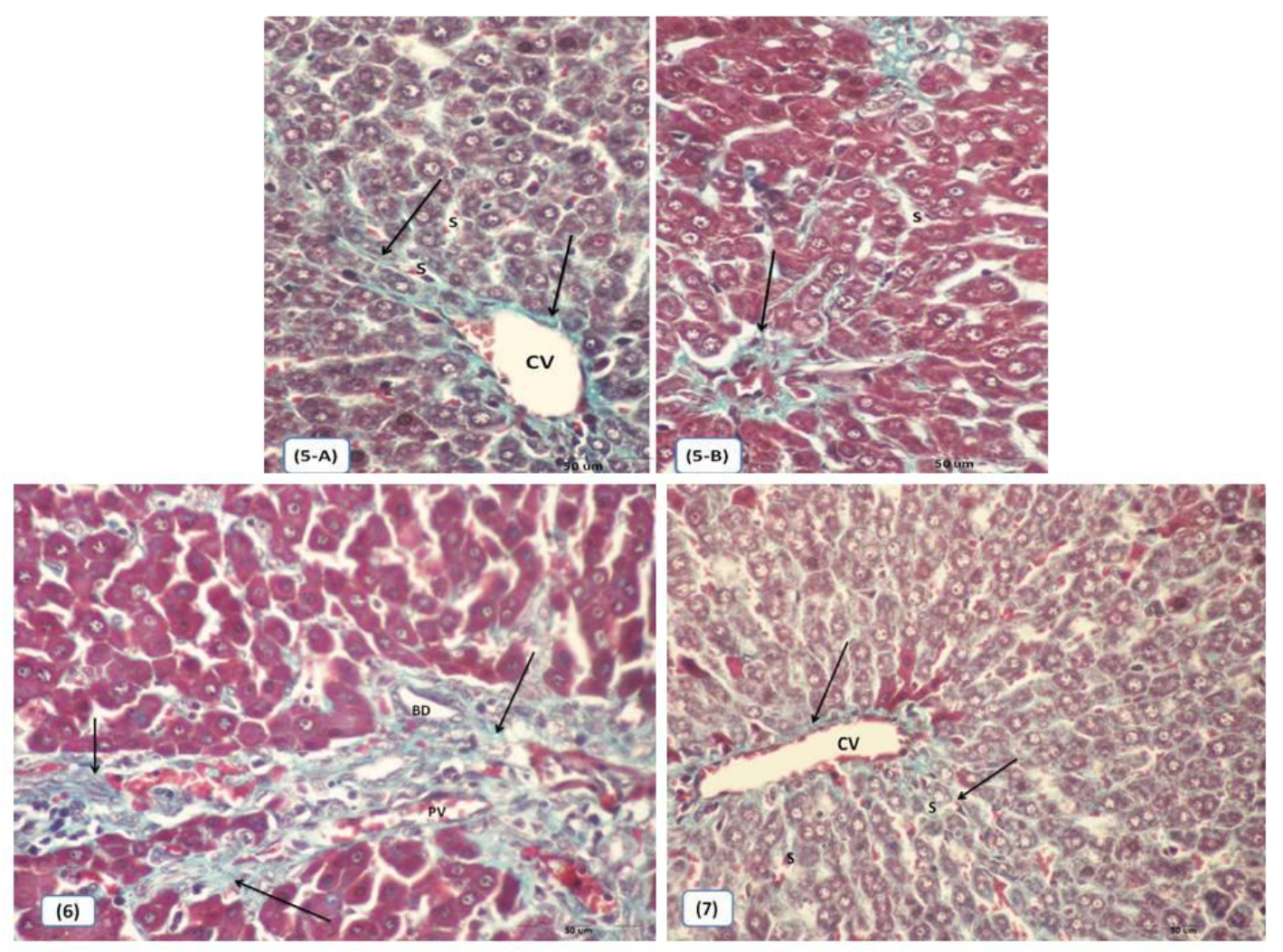

Figure (5): Photomicrographs of liver sections of control rats [A] and liver sections of rats treated with metformin [B] showing thin blue rims $(\uparrow)$ of collagen around central vein $(\mathrm{CV})$ and sinusoids $(\mathrm{S})$. (Masson's Trichrome Stain- Bar $=50$ $\mu \mathrm{m})$

Figure (6): Photomicrograph of liver section of fructose drinking rat showing marked collagen deposition $(\uparrow)$ in portal area; around portal vein (PV) and bile duct (BD) (Masson's Trichrome Stain - Bar $=50 \mu \mathrm{m}$ ).

Figure (7): Photomicrograph of liver section of fructose drinking rat treated with metformin showing weak collagen deposition $(\uparrow)$ around central vein $(\mathrm{CV})$ and sinusoids $(\mathrm{S})$ (Masson’s Trichrome Stain - Bar $=50 \mu \mathrm{m}$ ).

The mean percentage area of Nissl substance stained with cresyl violet stain was expressed in mean \pm SD and was compared using $\mathrm{F}$ test (ANOVA). Fructose group (5.89 \pm 2.31) displayed lower significant difference $(p=0.011)$ comparing with control group (11.92 \pm 3.16$)$ and showed insignificant lower difference as compared with metformin group $(10.45 \pm 2.86)$ and fructose treated metformin group $(8.46 \pm 1.68)$.

\section{Immunohistochemical Results:}

1. Immunostaining expression of caspase 3 in liver and brain sections:

Examined liver sections of both control and metformin treated rats displayed weak cytoplasmic immunostaining expression of caspase 3 as brown staining in tiny number of hepatocytes in addition to immunstaining reaction demarcates the sinusoids (Figure 14). Strong immunoreactivity of caspase 3 was observed in liver sections of fructose drinking rats; cytoplasmic immunoreaction was seen in many numbers of hepatocytes around central vein as compared with control sections (Figure 15). Moderate immunostaining reaction of caspase 3 was encountered in cytoplasm of some hepatocytes around central vein in liver sections of fructose drinking rat which treated with metformin as compared with their counterparts (Figure 16).

Brain sections immunostained for caspase 3 showed immunoreaction expression as cytoplasmic brown stain reaction confined to the neuronal cell body. Weak cytoplasmic immunostaining reactions in little number of neuronal cell bodies in cerebral cortex were observed in control and metformin groups (Figure 17 A\&B). Strong immunoreactivity of caspase 3 in many neuronal cell bodies was observed in cerebral cortex of fructose drinking rats (Figure $18 \mathrm{~A}$ ). Rats treated with metformin plus fructose consumption revealed decreased number of neuronal cells with moderate caspase 3 expressions. (Figure $18 \mathrm{~B})$. 

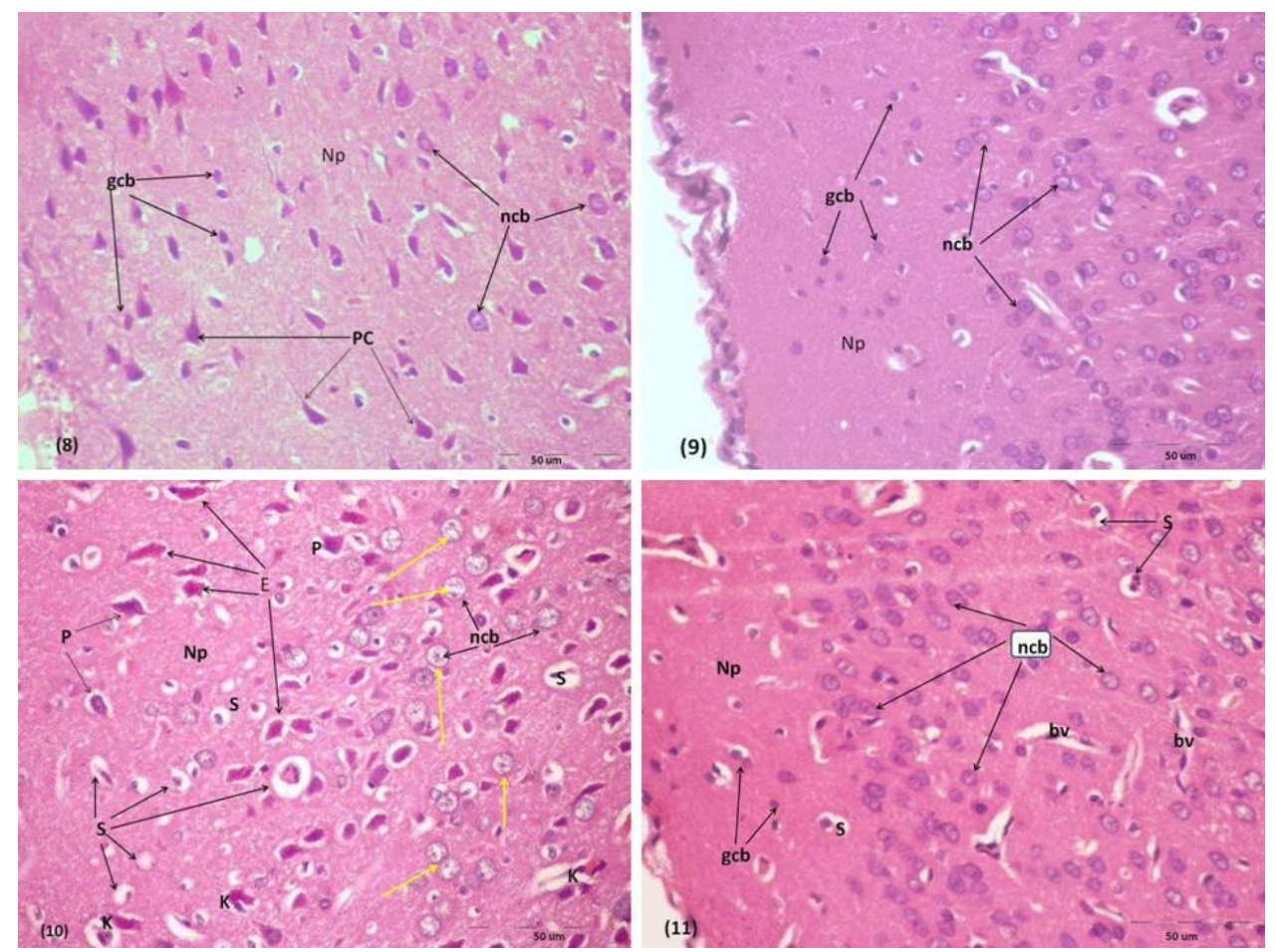

Figures (8): Photomicrograph of cerebral cortex of control brain showing pyramidal cells (PC) with apical dendrites, neuronal cell body (ncb) and glial cell body (gcb) are embedded in neuropil (Np). (H \& E; Bar=50 $\mu \mathrm{m}$ ).

Figures (9): Photomicrograph of brain of metformin treated rat showing more or less normal architecture of cerebral cortex. Note: neuronal cell body (ncb), glial cell body and neuropil (Np) . (H \& E; Bar=50 $\mu \mathrm{m}$ ).

Figure (10): Photomicrograph of brain cerebral cortex of fructose drinking rats showing increased degenerating neurons with eosinophilic cytoplasm (E), swelling and vacuolation (yellow arrows) in neuronal cell bodies (ncb), increased steatosis in nuropil (S), karyorrhectic nuclei (K) and pyknotic nuclei (P). (H \& E; Bar=50 $\mu \mathrm{m}$ ).

Figure (11): Photomicrograph of brain cerebral cortex of fructose drinking rats treated with metformin showing diminished steatosis (S), neuronal cell bodies (ncb), glial cell body in neuropil (Np) and blood vessels (bv). (H \& E; Bar $=50 \mu \mathrm{m})$
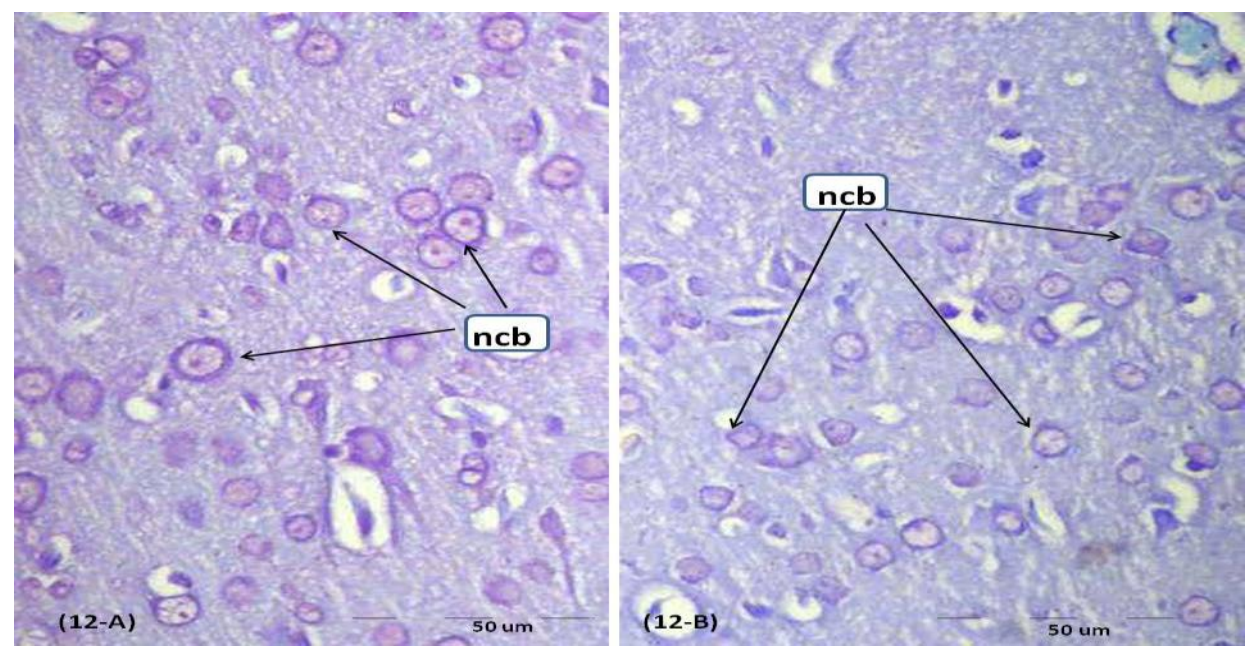

Figure (12 A): Photomicrograph of cerebral cortex of control rats showing normal histoarchitecture of neurons with round neuronal cell body (ncb) and cytoplasm with strongly stained Nissl substance. (Cresyl violet stain-Bar= 50 $\mu \mathrm{m})$

Figure (12 B): Photomicrograph of cerebral cortex of metformin treated rat showing more or less normally stained Nissl substance in cytoplasm of neuronal cell body (ncb). (Cresyl violet stain-Bar= $50 \mu \mathrm{m}$ ) 

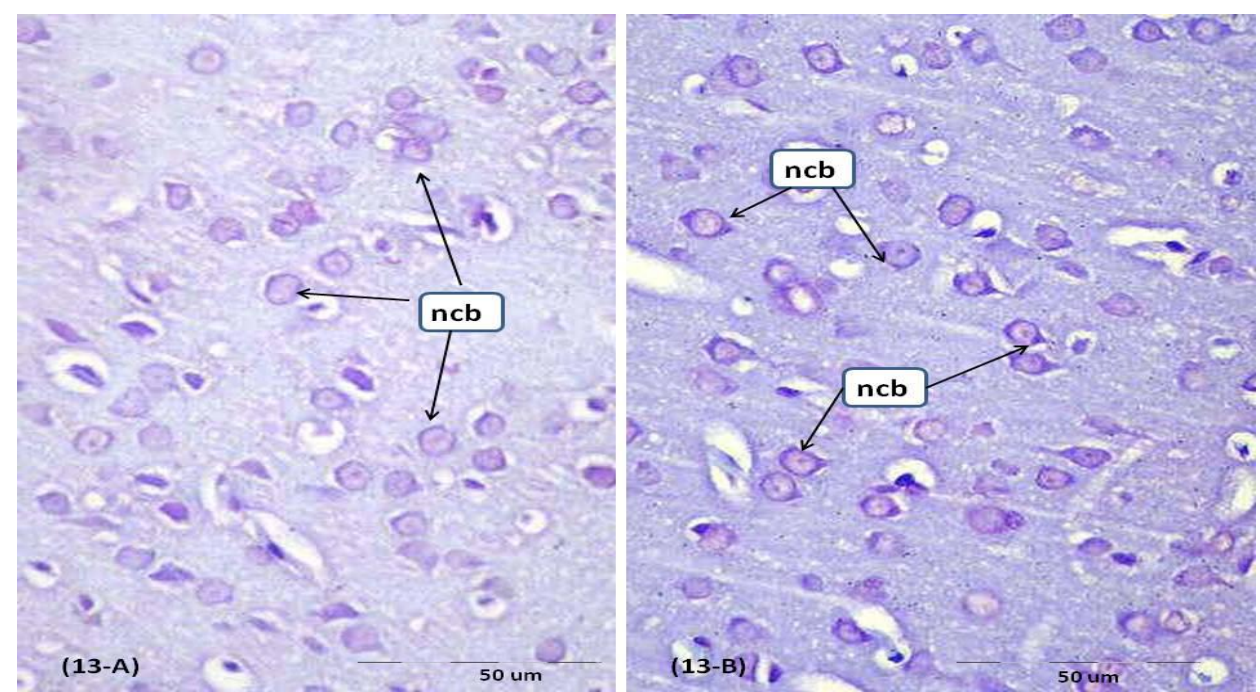

Figure (13 A): Photomicrograph of cerebral cortex in fructose drinking rats showing lightly stained reduced Nissl substance in cytoplasm of neuronal cell body $(\mathrm{nb})$. (Cresyl violet stain-Bar= $50 \mu \mathrm{m}$ )

Figure (13 B): Photomicrograph of cerebral cortex of rats treated metformin with fructose consumption showing moderate staining Nissl substance in cytoplasm of neuronal cell body (ncb). (Cresyl violet stain-Bar= $50 \mu \mathrm{m}$ )
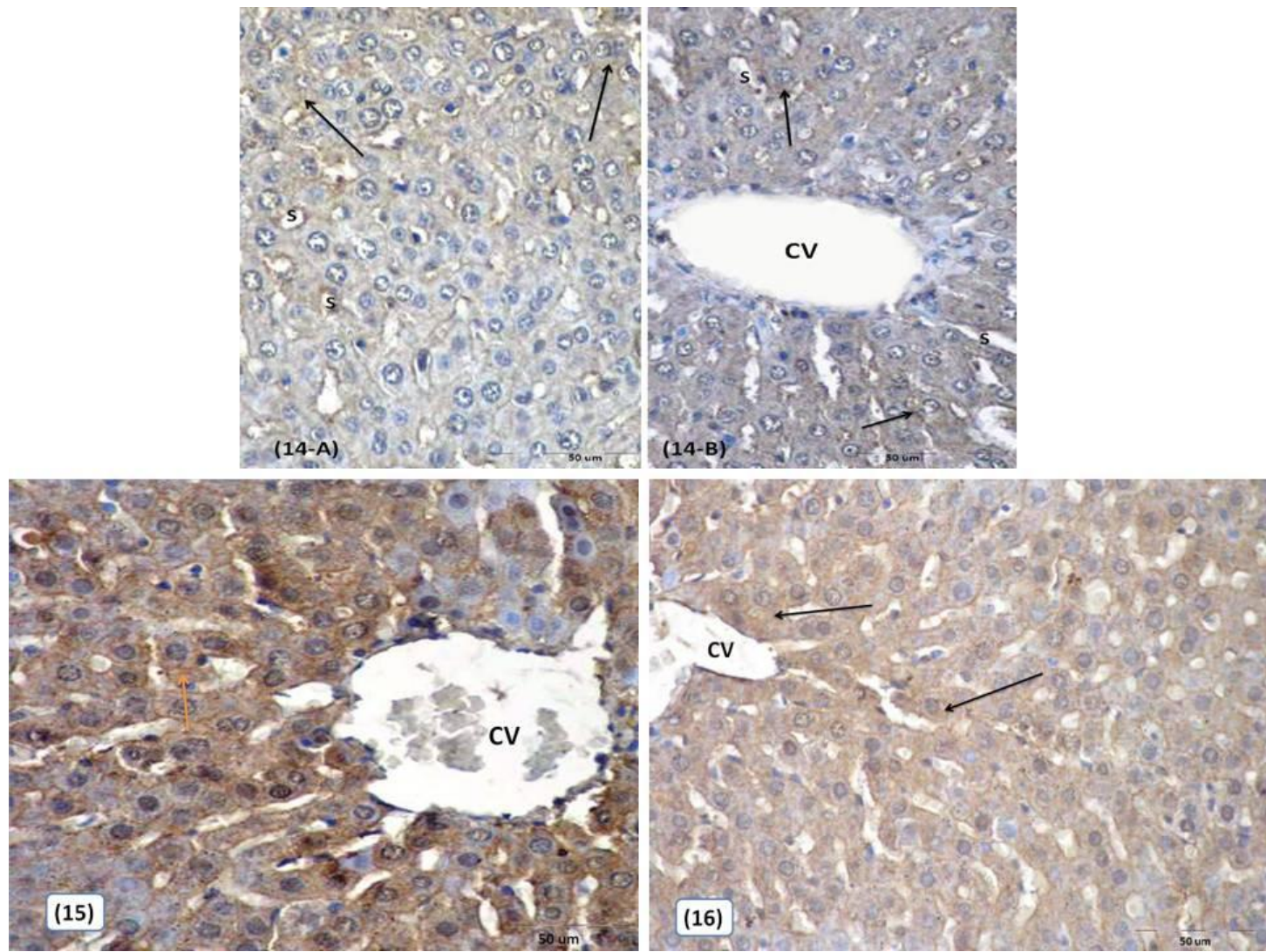

Figure (14): Photomicrographs of liver sections displaying weak cytoplasmic immunoreaction of caspase- 3 stained cells $(\uparrow)$ in little number of hepatocytes in control rats[A] and in rats treated with metformin [B]. Note the immunstaining reaction demarcates the sinusoids (S). (Avidin-biotin complex - Bar $=50 \mu \mathrm{m}$ )

Figure (15): Photomicrographs of liver sections of fructose drinking rat showing strong immunoreactivity $(\uparrow)$ of caspase 3 in large number of hepatocytes around central vein (CV) (Avidin-biotin complex - Bar $=50 \mu \mathrm{m}$ )

Figure (16): Photomicrograph of liver section of fructose drinking rat and treated with metformin showing immunoreaction of caspase $3(\uparrow)$ in cytoplasm of some hepatocytes around central vein (CV) in moderate staining. (Avidin-biotin complex - Bar $=50 \mu \mathrm{m}$ ) 

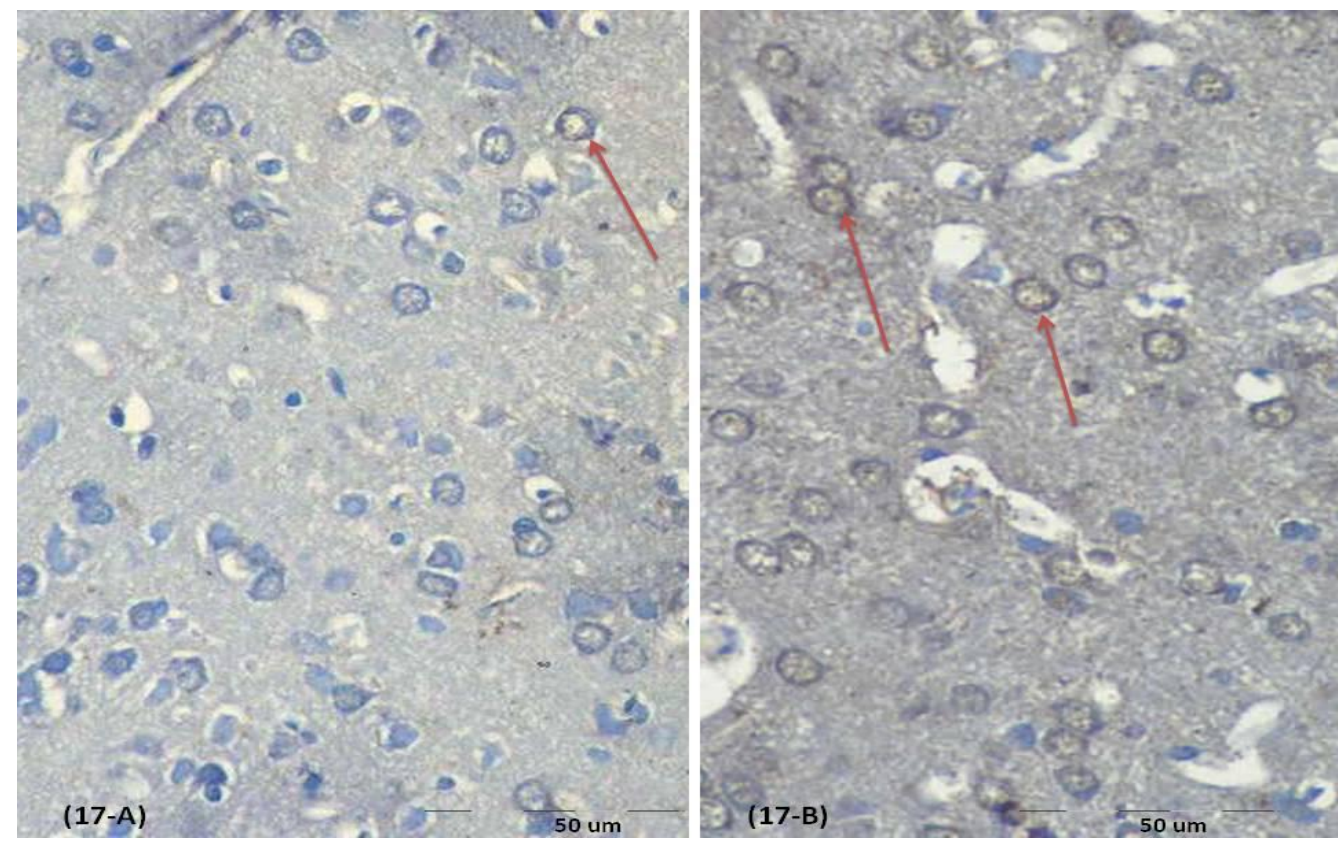

Figure (17): Photomicrographs of brain sections of control rat [A] and metformin treated rat [B] showing weak cytoplasmic immunostaining reactions $(\uparrow)$ in little number of neuronal cell bodies in cerebral cortex. (Avidin-biotin complex - Bar $=50 \mu \mathrm{m})$
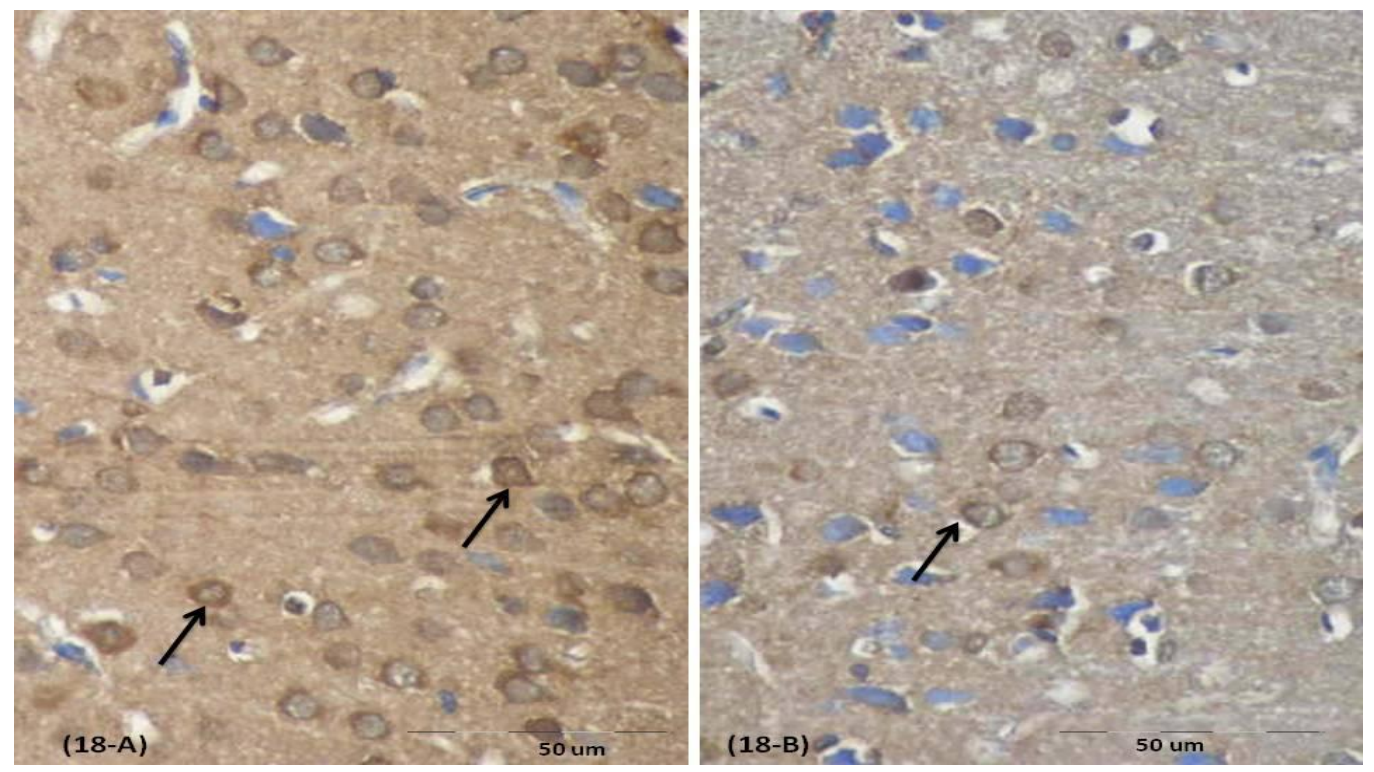

Figure (18): Photomicrographs of brain sections of [A] fructose drinking rat showing strong immunoreactivity of caspase 3 in many neuronal cell bodies and [B] fructose drinking rat treated with metformin showing decreased number of neuronal cells with moderate caspase 3 expressions (Avidin-biotin complex - Bar $=50 \mu \mathrm{m}$ )

By image analysis, caspase 3 immunostaining reactions in liver and brain were evaluated by two ways either by counting number of positive cells or calculating area with a positive reaction expressed in \% area and summarized in table (1). The number of positive cells was expressed in mean \pm SD and was compared using F test (ANOVA). The mean \% area was expressed in median (Min. - Max.) and compared using Kruskal Wallis test.

Fructose group was statistically higher significant difference $(p<0.001)$ in the mean number of positive cells in both liver and brain comparing with control and metformin groups. In addition to, fructose treated metformin group declared statistically lower significant 
difference $(\mathrm{p}<0.001)$ as compared with fructose group. Table (1) also showed that fructose group was statistically higher significant difference $(\mathrm{p}=0.001)$ in mean $\%$ area in both liver and brain comparing with the three other groups. Fructose treated metformin group showed higher significant difference $(p=0.001)$ in mean \% area in liver as compared with control and metformin groups and lower significant as compared with fructose group. Mean \% area of caspase 3 in brain revealed that fructose treated metformin group was significantly lower $(p=0.001)$ than fructose group.

1. Immunostaining expression of iNOS in liver and brain sections:

Liver sections displayed immunostaining expression of iNOS as brown weak staining reaction in tiny number of hepatocytes in liver sections of both control and treated metformin rats (Figure 19). Liver sections of fructose drinking rats exhibited many positive cells with strong brown stained iNOS expression as cytoplasmic staining in many hepatocytes in centrilobular and periportal area (Figure 20). The expression of iNOS displayed weak reaction in cytoplasm of hepatoctes in zone 1 and moderate iNOS expression in zone 3 in liver sections of fructose drinking rat treated with metformin as compared with counterparts (Figure 21).

Brain sections showed immunostaining reaction of iNOS as brown stain in cytoplasm of neuronal cell body. Control and metformin groups displayed very weak reaction of iNOS in little number of neuronal cells (Figure 22 A\&B). Fructose group showed increase in iNOS expression in most neuronal cells with marked intensity (Figure 23A). Fructose treated metformin group revealed weak reaction of iNOS immunostaining in some neuronal cells (Figure 23 B).

Immunostainig reaction of iNOS by image analysis in liver and brain was expressed in mean \% area and summarized in table (2). Fructose group showed statistically significant difference $(\mathrm{p}<0.01)$ in mean $\%$ area in liver and higher significant $(\mathrm{p}<0.001)$ in brain comparing with control and metformin groups. Fructose treated metformin group showed lower significant difference in liver $(\mathrm{p}<0.01)$ and in brain $(\mathrm{p}<0.001)$ as compared with fructose group.

\section{Discussion}

Fructose is widely used as a sweetener in the food and beverage industry, either as an integrant of the sucrose molecule or as a component of high fructose corn syrups. (Baena et al, 2015). The liver is the only organ in the body capable of managing fructose. ( Wei et al 2005). Liver converts fructose into fats (lipids) very rapidly and a substantial portion of that new fat remains in the liver, contributing to the fatty liver that's part of metabolic syndrome (Faeh et al, 2005 and Stanhope et al ,2013). The exposure of the liver to such large quantities of fructose led to rapid stimulation of lipogenesis and triglycerides accumulation, which in turn contributes to reduced insulin sensitivity (Moore et al, 2000).
The current results revealed the histopathologic features of liver injury in group of fructose drinking rats for 8 weeks as inflammatory cellular infiltration, many apoptotic figures and dilated sinusoids, fibrosis and macrosteatosis displayed hepatocytes with ballooned clear cytoplasm. Our present findings were in agreement with many previous studies which declared a variety of histological changes of liver tissue after fructose consumption (Ackerman et al, 2005, Sanchez-Lozada, et al, 2010 and El Ebiary and Khalaf, 2014). Fructose drinking in $10 \%$ for 10 days developed macrovesicular and microvesicular steatosis in male Wistar albino rats (Armutcu et al., 2005 ). Feeding high fructose and/or fat diet for over a month resulted in hepatic steatosis which further progressed to steatohepatitis with the involvement of cellular injury and apoptosis (Anstee and Goldin, 2006). Inflammatory cellular infiltration and focal necrosis appeared at 8 weeks of high fructose diet (32\% fructose) in Wistar rats (Zhang et al., 2013).

Macrosteatosis in portal triad area in zone 1 as seen in our result confirmed the result of Takahashi et al (2012) who demonstrated that the distribution of steatosis in the rats fed a high-fructose diet was characteristically predominant in zone 1.

Dilated sinusoids and hepatocytes with ballooned clear cytoplasm in the current result may be attributed to lipid accumulation thereby exacerbating hepatic steatosis. In accord, Helmy (2006) and Valla (2008) showed that steatosis directly interfered with the function of hepatocytes and damage to endothelial cells lining the sinusoids of the liver resulted in sinusoidal obstruction syndrome where sinusoidal dilation is considered as one of the hallmarks of sinusoidal obstruction syndrome. Moreover, ballooning of hepatocytes is a sign of cell membrane lipid peroxidation, with a resulting permeability disorder and considered as a phenomenon that, in general, follows steatosis, ballooning and hepatocytolisis; it may be interpreted as a consequence of liver injury and considered a significant histological feature to the determination of steatohepatitis. (Brunt et al., 2011 and Brunt, 2012)

The current results illustrated marked collagen deposition in portal area denoted presence of fibrosis in fructose group and evidenced by \% area analyzed by image analysis in higher significant $(8.04 \pm 1.53)$ comparing to control (2.01 \pm 0.91). These findings may be attributed to oxidative stress induced by fructose consumption and were in agreement with study of Delbosc et al. (2005). In explanation, Dowman et al. (2010) stated that increased ROS production inhibited the proliferation of mature hepatocytes; and the presence of non-differentiated hepatocytes in addition to mature ones being related to the progression to fibrosis. In the same context, Kawasaki et al. (2009) demonstrated that fructose feeding caused both microvesicular and macrovesicular steatosis with periportal fibrosis and lobular inflammation. Hepatic fibrogenesis was often associated with hepatocellular necrosis and inflammation (Zheng et al, 2003). 
Table 1.Comparison between number of positive cells and mean \% area occupied by caspase 3 reactions in rat liver and brain of all group

\begin{tabular}{|c|c|c|c|c|c|}
\hline Caspase 3 & $\begin{array}{c}\text { Group I } \\
\text { (Control) } \\
(\mathbf{n}=5)\end{array}$ & $\begin{array}{c}\text { Group II } \\
(\text { Metformin) } \\
(\mathbf{n}=5)\end{array}$ & $\begin{array}{c}\text { Group III } \\
\text { (Fructose) } \\
(\mathbf{n}=5)\end{array}$ & $\begin{array}{c}\text { Group IV } \\
\text { (Fructose } \\
\text { +metformin) } \\
(\mathbf{n}=5)\end{array}$ & $\mathbf{p}$ \\
\hline \multicolumn{6}{|l|}{ Liver } \\
\hline No. of positive cells & $5.0 \pm 1.58$ & $7.60 \pm 1.82$ & $27.60^{\mathrm{ab}} \pm 8.59$ & $13.80^{c} \pm 4.44$ & $<0.001^{*}$ \\
\hline$\%$ area & $2.42(1.11-3.62)$ & $3.64^{\mathrm{a}}(2.69-5.06)$ & $12.6^{\mathrm{ab}}(10.27-20.90)$ & $8.65^{\mathrm{abc}}(6.44-10.33)$ & $0.001^{*}$ \\
\hline \multicolumn{6}{|l|}{ Brain } \\
\hline No. of positive cells & $6.0 \pm 1.58$ & $7.20 \pm 2.59$ & $29.60^{\mathrm{ab}} \pm 6.88$ & $10.60^{c} \pm 3.51$ & $<0.001^{*}$ \\
\hline$\%$ area & $2.0(0.84-4.30)$ & $5.68^{\mathrm{a}}(2.81-8.66)$ & $16.39^{\mathrm{ab}}(12.26-23.48)$ & $6.93^{\mathrm{ac}}(5.27-9.65)$ & $0.001^{*}$ \\
\hline
\end{tabular}

Normally quantitative data was expressed in mean \pm SD and was compared using $\mathrm{F}$ test (ANOVA). abnormally distributed data was expressed in median (Min. - Max.) and was compared using Kruskal Wallis test

a: Significant with group I

c: Significant with group III b: Significant with group II

*: Statistically significant at $\mathrm{p} \leq 0.05$

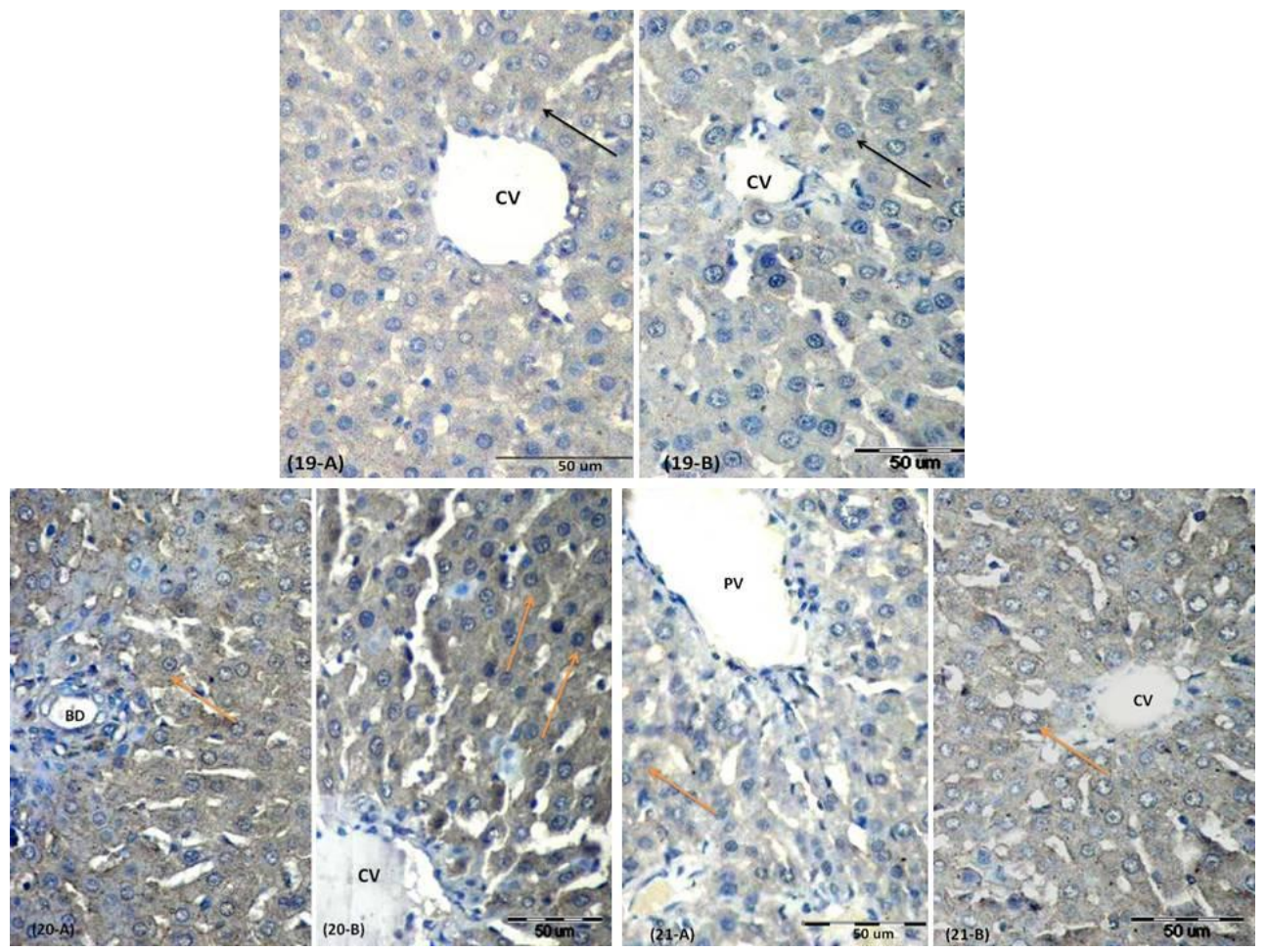

Figure (19): Photomicrographs of liver sections showing tiny number of hepatocytes with weak iNOS expression ( $\uparrow)$ in control rats [A] and rats treated with metformin [B] around central vein (CV). (Avidin-biotin complex - Bar $=50 \mu \mathrm{m}$ ) Figure (20): Photomicrographs of liver sections of fructose drinking rat showing many positive cells with strong brown stained iNOS expression in their cytoplasm in zone 1 [A] and zone 3 [B]. Note: central vein (CV) and bile duct (BD). (Avidin-biotin complex - Bar $=50 \mu \mathrm{m}$ )

Figure (21): Photomicrographs of liver sections of fructose drinking rat and treated with metformin showing weak iNOS expression in cytoplasm of hepatoctes in zone 1 [A] and moderate iNOS expression ( $\uparrow$ ) in hepatocytes in zone 3 [B] . Note: portal vein (PV) and central vein (CV). (Avidin-biotin complex - Bar $=50 \mu \mathrm{m})$ 

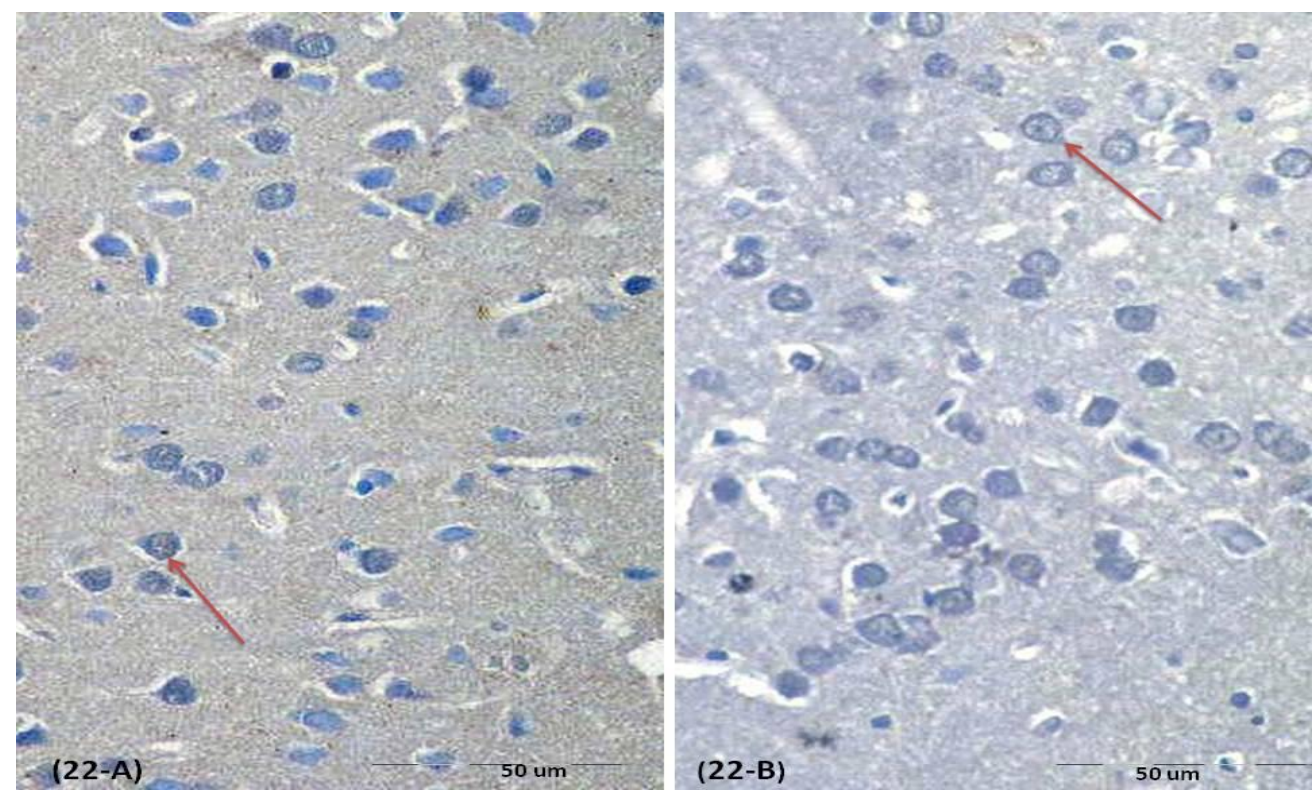

Figure (22): Photomicrographs of brain sections showing immunostaining reaction of iNOS in cerebral cortex of control [A] and metformin [B] groups displayed very weak reaction of iNOS in little number of neuronal cells ( $\uparrow$ ). (Avidinbiotin complex - Bar $=50 \mu \mathrm{m}$
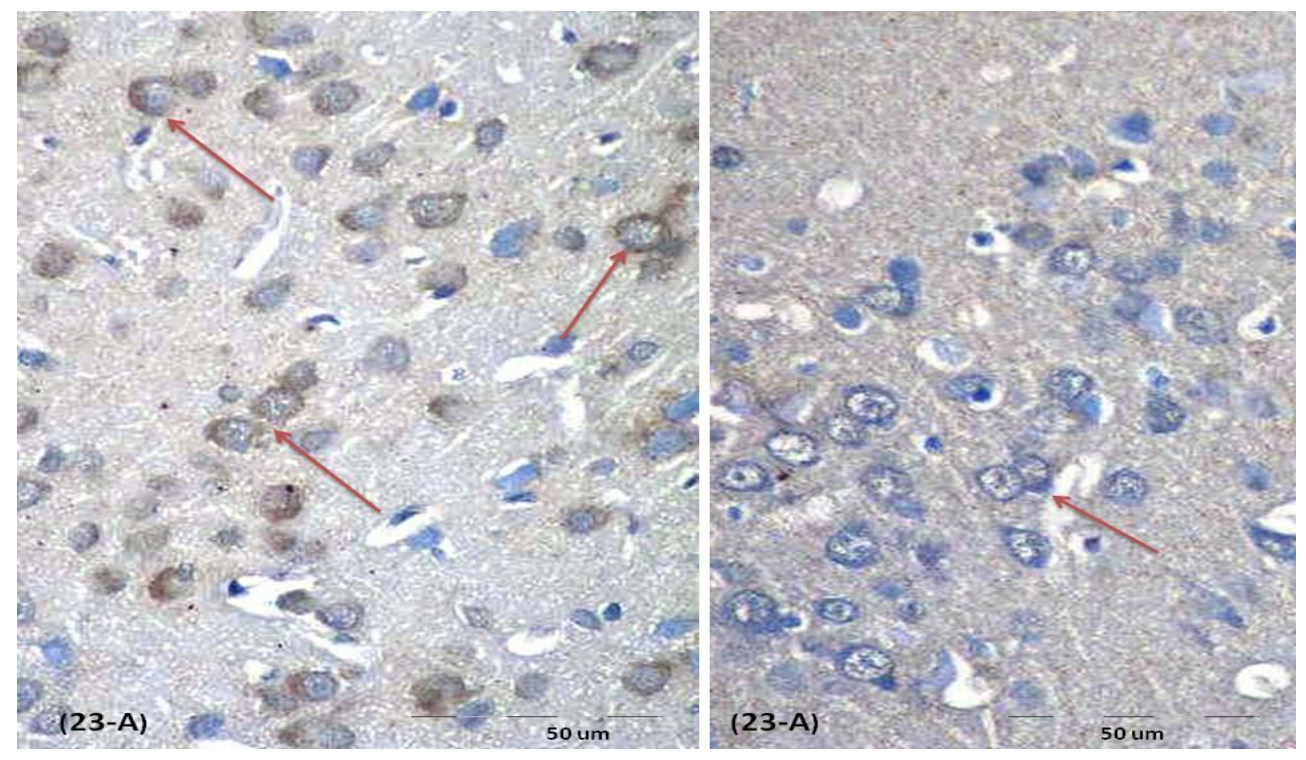

Figure (23): Photomicrographs of brain sections of fructose drinking rat [A] showing increase in iNOS expression in most neuronal cells with marked intensity. [B] Fructose treated metformin group showing weak reaction of iNOS immunostaining in some neuronal cells. (Avidin-biotin complex - Bar $=50 \mu \mathrm{m}$ ). 
Table (2): Mean \% area occupied by iNOS reaction in the rat liver and brain in all groups.

\begin{tabular}{|c|c|c|c|c|c|}
\hline iNOS & $\begin{array}{c}\text { Group I } \\
(\text { Control) } \\
(n=5)\end{array}$ & $\begin{array}{c}\text { Group II } \\
\text { (Metformin) } \\
(\mathbf{n}=5)\end{array}$ & $\begin{array}{c}\text { Group III } \\
\text { (Fructose) } \\
(\mathbf{n}=5)\end{array}$ & $\begin{array}{c}\text { Group IV } \\
\text { (Fructose } \\
+ \text { metformin) } \\
(\mathbf{n}=5)\end{array}$ & $\mathbf{p}$ \\
\hline Liver & $3.45 \pm 1.16$ & $3.54 \pm 1.16$ & $10.03^{\mathrm{ab}} \pm 2.39$ & $4.93^{\mathrm{C}} \pm 1.37$ & $<0.01^{*}$ \\
\hline Brain & $2.11 \pm 0.60$ & $2.53 \pm 0.91$ & $10.29^{\mathrm{ab}} \pm 3.19$ & $3.73^{c} \pm 0.99$ & $<0.001^{*}$ \\
\hline
\end{tabular}

Normally quantitative data was expressed in mean \pm SD and was compared using $F$ test (ANOVA)

a: Significant with group I b: Significant with group II

c: Significant with group III $\quad *$ : Statistically significant at $\mathrm{p} \leq 0.05$

It is of interest to notice that metformin treatment plus fructose drinking in the current result eliminated histopathological changes in liver tissue; decreased apoptosis , diminished cellular infiltration and steatosis and decreased collagen deposition with lower significant difference in $\%$ area $\left(4.93^{\mathrm{abc}} \pm 0.80\right)$ compared with fructose drinking group ( $8.04 \pm 1.53)$. These results may be attributed to the vital role of metformin in protecting hepatocytes from oxidative stress by decreasing steatosis and fibrosis suggesting that metformin has an ability to recover liver injury.

These findings are in line with the results obtained by many studies; metformin protected against fructoseinduced liver steatosis (Spruss et al., 2012), inhibited the formation of hepatic fibrosis and steatosis in type 2 diabetes (Qiang et al, 2010 ), and described as an efficient treatment for NASH and hepatic inflammation ( Kita et al, 2012). It protected liver by decreasing hepatocyte fat deposition and inhibited inflammatory response in nonalcoholic fatty liver disease (NAFLD) (Woo et al, 2014) .

Fructose consumption for 8 weeks in the present study revealed deleterious histopathological changes in brain cortex manifested by increased degenerating neurons with eosinophilic cytoplasm, swelling and vacuolation in neuronal cell bodies, increased steatosis in nuropil, karyorrhectic and pyknotic nuclei. These findings may be due to increased oxidative stress and were in agreement with many recent studies which have specifically described neurotoxicity elicited by fructose, inducing oxidative stress, inhibiting acetylcholinesterase activity and affecting rat brain mitochondrial function (Guimarães et al. 2014, Lopes et al. 2014, Mortensen et al.2014).

Our present results showed that metformin treatment plus fructose drinking enhanced normal appearance of neuronal cell and diminished steatosis in neuropil. In accord, El-Mir, et al (2008) showed the neuroprotective role of metformin against apoptotic cell death in primary cortical neurons and proposed that metformin can function as new therapeutic tool for diabetes-associated neurodegenerative disorders. Metformin can cross the blood-brain barrier and have specific pharmacological effects on the central nervous system (Labuzek et al, 2010) and it is a potential therapy for injured or degenerating nervous system in cellular and animal models (Wang, et al, 2012, Ma et al, 2007 and Nath et al , 2009).

Cresyl violet staining in the current study confirmed the impairment of neuronal cell body after fructose consumption and showed lightly stained Nissl substance with lower significant difference in mean \% area (5.89 \pm 2.31) comparing with control group (11.92 \pm 3.16). Metformin treatment showed improvement in the Nissl substance staining with mean $\%$ area $(8.46 \pm 1.68)$. In this context, Akinola et al (2012) in their study on brain of the diabetic rats showed structural impairment characterized by loss of axonal myelin sheath and poor Nissl staining outcome suggesting loss of Nissl substance and nuclear DNA in the somata of the diabetic brain. In agreement, Nagayach et al, (2014) showed that staining with cresyl violet depicted a marked cellular degeneration in cerebellum following streptozotocin (STZ) -induced diabetes compared with control cerebellar cells which were darkly stained and attributed to loss of Nissl substance in diabetic cerebellar cells.

Caspases are cysteine-aspartyl specific proteases that play a key role in apoptosis (Creagh et al., 2003). Caspase-3 is one of the effectors caspases that has been implicated as a key protease cleaving multiple cellular substrates, including components related to DNA repair and regulation, to bring the cell to its demise (Woo et al., 1998 and Zhang et al., 2005). Caspase- 3 is a potent, terminal caspase that plays a crucial role in executing apoptosis through the mitochondrial-dependent pathway (Gill et al., 2002).

The present results showed strong immunoreactivity of caspase-3 in both liver and brain sections of fructose drinking rats which confirmed by image analysis and revealed higher significant difference in number of positive cells as well as in mean \% area as compared with other 
groups. This increment in caspase-3 suggested increased apoptosis in response to oxidative stress.

In the same context, Nedzvetsky et al. ( 2012) stated that damage in liver and brain in diabetic rats were mostly due to excessive free radical generation and development of oxidative stress. Increased activity of caspase-3 in rat liver was observed in the liver of rats with experimentally induced type 2 diabetes (Popova et al., 2013).

It was also demonstrated that oxidative stress-induced neuronal and Schwann cells death via increased caspase-3 activity was observed in diabetic neuropathy (Vincent et al., 2002). Also, Zhao et al. (2012) proved that diabetes up regulated the expression of Bax and caspase- 3 which led to apoptosis of the pyramidal neurons in STZ - induced diabetic rats .

Metformin treatment plus fructose consumption in present study revealed moderate immunoreaction of caspase-3 in liver and brain. Lower significant difference in positive cell numbers $(13.80 \pm 4.44)$ and $(10.60 \pm 3.51)$ as well as in \% area 8.65 (6.44 - 10.33) and $6.93(5.27$ - 9.65) in hepatocytes and neuronal cells respectively comparing to their counterparts in fructose group.

It is of interest to notice higher significant in \% area of caspase- 3 in group treated with metformin plus fructose than in control group of liver and brain rather than positive cell numbers. This higher significantly in \% area may be attributed to increased immunstaining positivity which calculated the all \% area stained with brown color either weak or strong cytoplasmic reaction.

Many investigations indicated that during oxidative stress elevation of ROS and reduction of superoxide dismutase were accompanied by induction of iNOS and increased NO-ROS reaction was found in diabetic tissues (Ferrini et al, 2006 and McCann et al, 2005). High-fructose diet contributes to excessive formation of reactive oxygen species. This leads to oxidative stress and its associated complications like chronic inflammation, characterized by abnormal cytokine production (TNF- $\alpha$ ) and the activation of a cascade of inflammatory signaling pathways (El-Abhar and Schaalan, 2012)

Our present results declared many positive cells with increased iNOS immunostaining in both liver and brain of fructose group. The mean \% area revealed statistically higher significant difference in fructose group in both liver $(10.03 \pm 2.39)$ and brain (10.29 \pm 3.19$)$ comparing with control and metformin groups.

The current findings may be attributed to increased oxidative stress and confirmed many findings obtained by previous studies either on liver or brain.

iNOS is virtually absent in the normal liver, but highly up regulated in response to a variety of inflammatory or oxidative stresses. This led to the common postulate that iNOS contributed to maintaining sinusoidal perfusion following stress conditions (Shibayama and Nakata, 1992). The induction of iNOS in the liver seemed to correlate with fatty changes and the expression of iNOS is up-regulated by most inducers of obesity, hyperglycemia, and insulin resistance, including free fatty acids, endotoxins, and oxidative stress (Fujimoto et al., 2005). In accordance, the result of Ha and Chae (2010) showed that iNOS is more highly expressed in high- fat -diet induced steatohepatitis.

Neurotoxicity induced by fructose was mediated through oxidative stress and inflammatory parameters in rat brain (Lopes et al. 2014). Excessive nitric oxide production via iNOS has an essential role in neuronal cell damage. (Wei, 2000 and Bal-Price and Brown, 2001). It was observed that excessive local levels of NO during inflammation may damage axons and growth cones (Zochodne and Levy, 2005).

Preliminary studies of Galea et al. (1994) and Nunokawa et al. (1993) showed that iNOS activity has been demonstrated in a wide variety of stimulated cells like macrophages, neutrophils, vascular smooth cells, and glial cells in the CNS.

Metformin treatment plus fructose drinking revealed weak to moderate iNOS immunostainig reaction in liver and weak reaction in brain as compared with fructose group. Mean \% area of iNOS stain showed lower significant difference in liver $(4.93 \pm 1.37)$ and brain $(3.73 \pm 0.99)$ comparing with fructose group denoted the vital role of metformin in antagonizing detrimental effect of fructose on liver and brain tissues.

Chakraborty et al. (2011) explored that metformin treatment restores the antioxidant status, enzymatic activity and inflammatory parameters in type 2 diabetic patients and it is more effective in reducing oxidative stress in cases with type 2 diabetes (Esteghamati, 2013).

\section{References}

Ackerman, Z., Oron-Herman, M., Grozovski, M., Rosenthal, T., Pappo,. O, Link, G., Sela, B.A. (2005). Fructose-induced fatty liver disease: hepatic effects of blood pressure and plasma triglyceride reduction Hypertension, 45(5): 1012-1018.

Akinola, O. Gabriel, M., Suleiman, A , Olorunsogbon, F. (2012). Treatment of Alloxan-Induced Diabetic Rats with Metformin or Glitazones is Associated with Amelioration of Hyperglycaemia and Neuroprotection. The Open Diabetes Journal, 5: 8-12

Altaş, M., Var, A., Köse, C., Özbilgin, K., Arı, Z., (2010). Endothelial dysfunction in high fructose containing diet fed rats: Increased nitric oxide and decreased endothelin-1 levels in liver tissue. Dicle Tıp Dergisi / Dicle Medical Journal Cilt., 37 (3): 193-198

Anstee, Q.M., Goldin, R.D.(2006). Mouse models in non-alcoholic fatty liver disease and steatohepatitis research. Int J Exp Pathol., 87(1):1-16.

Armutcu, F., Coskun, O., Gürel, A., Kanter, M., Can, M., Ucar, F., Unalacak, M. (2005). Thymosin alpha 1 attenuates lipid peroxidation and improves fructose-induced steatohepatitis in rats. Clin. Biochem., 38(6): 540-547.

Baena, M., Sangüesa, G., Hutter, N., Sánchez, R.M., Roglans, N., Laguna, J.C., Alegret, M.(2015). 
Fructose supplementation impairs rat liver autophagy through mTORC activation without inducing endoplasmic reticulum stress. Biochim Biophys Acta. ;1851 (2):107116. doi: 10.1016/j.bbalip.2014.11.003.

Bal-Price, A., Brown, G.C. (2001). Inflammatory neurodegeneration mediated by nitric oxide from activated glia-inhibiting neuronal respiration, causing glutamate release and excitotoxicity. J Neurosci., 21(17): 6480-6491.

Bancroft, D.J., Stevens, A.( 2002). Theory and Practice of Histology Technique. $4^{\text {th }}$ ed. Churchill Livingstone, Eduinburgh, London, New York ; pp116-117.

Basciano, H., Federico, L., Adeli K.( 2005). Fructose, insulin resistance and metabolic dyslipidemia. Nutr. Metab., 2:5-10.

Brunt, E. M. , Kleiner, D. E. , Wilson, L. A. , Belt, P. , Neuschwander-Tetri, B. A. (2011). "Nonalcoholic fatty liver disease (NAFLD) activity score and the histopathologic diagnosis in NAFLD: distinct clinicopathologic meanings," Hepatology, 53(3): 810-820.

Brunt, E. M.( 2012). Nonalcoholic fatty liver disease: what the pathologist can tell the clinician. Dig Dis. ;30 (1) :61-68.

Chakraborty, A., Chowdhury, S., Bhattacharyya, M. (2011). Effect of metformin on oxidative stress, nitrosative stress and inflammatory biomarkers in type 2 diabetes patients. Diabetes Res Clin Pract. , 93(1):56-62.

Creagh, E.M., Conroy, H., Martin, S.J. (2003). Caspase-activationpathways in apoptosis and immunity," Immunological Reviews, 193: 10-21.

de la Monte, S. M. (2009). Insulin resistance and Alzheimer's disease. BMB Rep 42, 475-481.

Delbosc S, Paizanis E, Magous R., Araiz,C., Dimo, T., Cristol, J.P., Cros, G., Azay, J.( 2005). Involvement of oxidative stress and NADPH oxidase activation in the development of cardiovascular complications in a model of insulin resistance, the fructose-fed rat. Atherosclerosis; 179:43-49

Dowman, J. K. , Tomlinson, J.W., Newsome' P.N (2010). Pathogenesis of non-alcoholic fatty liver disease Q J Med., 103(2) :71-83

Earnshaw, W.C., Martins, L.M., Kaufmann, S.H. (1999). Mammalian caspases: structure, activation, substrates and functions during apoptosis. Rev. Biochem., 68:282-424.

Edwards, J.L., Vincent, A.M., Cheng, H.T., Feldman, E.L.(2008). Diabetic neuropathy mechanisms to management. Pharmacol. Ther., 120:1-34.

El-Abhar, H.S., Schaalan, M.F.

(2014). Phytotherapy in diabetes: Review on potential mechanistic perspectives. World J Diabetes. , 5(2):176-197.

El Ebiary, F. H. and Khalaf, G. (2014). The effect of high fructose diet on the structure of liver of albino rat and the possible protective role of cinnamon. Light and electron microscopic study. IOSR Journal of Dental and Medical Sciences (IOSR-JDMS), 13 ( 6 ): 46-53
El-Mir, M.Y., Detaille, D., R-Villanueva, G., Delgado-Esteban, M., Guigas, B., Attia, S., Fontaine, E., Almeida, A., Leverve, X.( 2008) Neuroprotective role of antidiabetic drug metformin against apoptotic cell death in primary cortical neurons. J Mol Neurosci. , 34(1):77-87.

Esteghamati, A., Eskandari, $\quad$ D., Mirmiranpour, H., Noshad, S., Mousavizadeh, M., Hedayati, M., Nakhjavani, M. (2013). Effects of metformin on markers of oxidative stress and antioxidant reserve in patients with newly diagnosed type 2 diabetes: a randomized clinical trial. Clin Nutr., 32(2):179-85.

Faeh, D., Minehira, K., Schwarz, J.M., Periasamy, R., Park, S., Tappy, L.(2005). Effect of fructose overfeeding and fish oil administration on hepatic de novo lipogenesis and insulin sensitivity in healthy men. Diabetes. ;54 (7):1907-1913.

Ferrini, M.G., Nolazco, G., Vernet, D., GonzalezCadavid, N.F., Berman, J.(2006). Increased vaginal oxidative stress, apoptosis, and inducible nitric oxide synthase in a diabetic rat model: implications for vaginal fibrosis. Fertil Steril. , 86(4):1152-1163.

Fujimoto, M., Shimizu, N., Kunii, K., Martyn, J.A., Ueki, K., Kaneki, M.(2005). A role for iNOS in fasting hyperglycemia and impaired insulin signaling in the liver of obese diabetic mice. Diabetes. ,54(5):1340-1348.

Galea E, Reis DJ, Feinstein DL: Cloning and expression of inducible nitric oxide synthase from rat astrocytes. J Neurosci Res 1994, 37:406-414

Geller, D.A., Lowenstein, C.J., Shapiro, R.A., Nussler, A.K., Di, S.M., Wang, S.C., Nakayama, D.K., Simmons, R.L., Snyder, S.H., Billiar, T.R.(1993). Molecular cloning and expression of inducible nitric oxide synthase from human hepatocytes. Proc Natl Acad Sci USA, 90:3491-3495.

Gill, R., Soriano, M., Blomgren, K., Hagberg, H., Wybrecht, R., Miss, M.T., Hoefer, S., Adam, G., Niederhauser, O., Kemp, J.A., Loetscher, H.(2002). Role of caspase-3 activation in cerebral ischemia-induced neurodegeneration in adult and neonatal brain. J Cereb Blood Flow Metab. , 22(4):420-430.

Guimarães, C.A., Biella, M.S. , Lopes, A., Deroza PFOliveira, M.B. , Macan, T.P., Streck, E.L. , Ferreira, G.C., Zugno, A.I., Schuck, P.F. (2014). In vivo and in vitro effects of fructose on rat brain acetylcholinesterase activity: an ontogenetic study. An Acad Bras Cienc., 86: 1919-1926.

Ha, S.K., Chae, C. (2010). Inducible nitric oxide distribution in the fatty liver of a mouse with high fat dietinduced obesity. Exp Anim., 59(5):595-604.

Helmy, A. ( 2006). Review article: Updates in the pathogenesis and therapy of hepatic sinusoidal obstruction syndrome. Aliment Pharmacol Ther. , 23:11-25

Huang, Y.C., Hsu, C.C., Lin, W.C., Yin, T. K., Huang, C.W., Wang, P.W., Chang. H.H. , Chiu, N.T. (2014). Effects of metformin on the cerebral metabolic changes in type 2 diabetic patients. Scientific World Journal Volume 2014, Article ID 694326, 8 pages 
Ingaramo, P.I., Ronco, M.T., Francés, D.E., Monti, J.A., Pisani, G.B., Ceballos, M.P., Galleano, M., Carrillo, M.C., Carnovale, C.E.(2011) Tumor necrosis factor alpha pathways develops liver apoptosis in type 1 diabetes mellitus. Mol. Immunol., 48 (12-13): 1397-1407

Kawasaki, T., Igarashi, K., Koeda, T., Sugimoto, K., Nakagawa, K., Hayashi, S., Yamaji, R., Inui, H., Fukusato, T., Yamanouchi, T. (2009). Rats fed fructose-enriched diets have characteristics of nonalcoholic hepatic steatosis. J Nutr., 139:2067-2071

Kim, B, Feldman, E.L.( 2012). Insulin resistance in the nervous system. Trends Endocrinol. Metab., 23(3):133141.

Kita, Y., Takamura, T., Misu, H., Ota, T., Kurita, S., Takeshita, Y., Uno, M., Matsuzawa-Nagata, N., Kato, K., Ando, H., Fujimura, A., Hayashi, K., Kimura, T., Ni, Y, Otoda, T., Miyamoto, K., Zen, Y., Nakanuma, Y., Kaneko, S.(2012) Metformin prevents and reverses inflammation in a non-diabetic mouse model of nonalcoholic steatohepatitis. PLoS One, 7:e43056.

Łabuzek, K., Suchy, D., Gabryel, B., Bielecka, A., Liber, S., Okopień, B. (2010). Quantification of metformin by the HPLC method in brain regions, cerebrospinal fluid and plasma of rats treated with lipopolysaccharide," Pharmacological Reports, 62(5): 956965.

Lopes, A., Vilela, T.C., Taschetto, L., Vuolo, F., Petronilho. F., Dal-Pizzol, F., Streck, E.L. , Ferreira, G.C., Schuck, P.F. (2014). Evaluation of the effects of fructose on oxidative stress and inflammatory parameters in rat brain. Mol Neurobiol., 50: 1124-1130.

Luna, L.G. (1968). Manual of histologic Staining Methods of the Armed forces institute of pathology. $3^{\text {rd }}$ ed. New York: McGraw Hill bock Co.

Lyons, C.R., Orloff, G.J., Cunningham, J.M. (1992). Molecular cloning and functional expression of an inducible nitric oxide synthase from a murine macrophage cell line. J Biol Chem. , 267:6370-6374

Ma, T.C., Buescher, J.L., Oatis, B., Funk, J.A., Nash, A.J., Carrier, R.L., Hoyt, K.R. (2007). Metformin therapy in a transgenic mouse model of Huntington's disease. Neurosci Lett. , 411(2):98-103.

McCann, S.M., Mastronardi, C., de Laurentiis, A., Rettori, V. (2005). The nitric oxide theory of aging revisited. Ann N Y Acad Sci. ,1057: 64-84.

Moore, M.C., Cherrington, A.D., Mann, S.L., Davis, S.N.( 2000). Acute fructose administration decreases the glycemic response to an oral glucose tolerance test in normal adults. J Clin Endocrinol Metab., 85(12):45154519.

Morino, K., Petersen, K.F., Shulman, G.L. (2006). Molecular mechanisms of insulin resistance in humans and their potential links with mitochondrial dysfunction. Diabetes, 55(Suppl 2):S9-S15
Mortensen, O.H., Larsen, L.H., Ørstrup, L.K., Hansen, L.H., Grunnet, N. , Quistorff, B.( 2014). Developmental programming by high fructose decreases phosphorylation efficiency in aging offspring brain mitochondria, correlating with enhanced UCP5 expression. J Cereb Blood Flow Metab., 34: 1205-1211

Nagayach, A., Patro, N., Patro, I. (2014). Experimentally induced diabetes causes glial activation, glutamate toxicity and cellular damage leading to changes in motor function. Front Cell Neurosci. , 8:355. pp: 1-15

Nakayama, D.K., Geller, D.A., Lowenstein, C.J., Davies, P., Pitt, B.R., Simmons, R.L., Billiar, T.R. (1992). Cytokines and lipopolysaccharide induce nitric oxide synthase in cultured rat pulmoary artery smooth muscle. Am J Respir Cell Mol Biol., 7:471-476.

Nath, N., Khan, M., Paintlia, M.K., Singh, I., Hoda, M.N., Giri, S.(2009) "Metformin attenuated the autoimmune disease of the central nervous system in animal models of multiple sclerosis," Journal of Immunology, 182(12): 8005-8014.

Nedzvetsky, V., Andrievsky, G., Chachibaia, T., Tykhomyrov, A. (2012). Differences in antioxidant/protective efficacy of hydrated C60 fullerene nanostructures in liver and brain of rats with streptozotocininduced diabetes. J. Diabetes Metab., 3(8): 1-9.

Neumann, K. F., Rojo, L., Navarrete, L. P., Farias, G., Reyes, P. and Maccioni, R. B. (2008). Insulin resistance and Alzheimer's disease: molecular links \& clinical implications. Curr Alzheimer Res 5, 438-447.

Nunokawa, Y., Ishida, N., Tanaka, S. (1993). Cloning of inducible nitric oxide synthase in rat vascular smooth muscle cells. Biochem Biophys Res Commun., 191:89-94

Ouyang, X., Cirillo, P., Sautin, Y., McCall, S., Bruchette, J.L., Diehl, A.M., Johnson, R.J., Abdelmalek, M.F. (2008). Fructose consumption as a risk factor for nonalcoholic fatty liver disease. J. Hepatol., 48:993-999.

Paolisso, G., Gambardella, A., Tagliamonte, M.R., Saccomanno, F., Salvatore, T., Gualdiero. P., D'Onofrio, M.V., Howard, B.V.( 1996). Does free fatty acid infusion impair insulin action also through an increase in oxidative stress? J Clin Endocrinol Metab 1996; 81(12):4244-4248.

Popova, T.N., Agarkov, A.A., Verevkin, A.N. (2013). Intensity of Free Radical Processes in Rat Liver under Type 2 Diabetes and Introduction of Epifamin. Acta Naturae. , 5(4):118-122.

Powell, L.A., Warpeha, K.M. Xu, W., Walker, B., Trimble, E.R. (2004). High glucose decreases intracellular glutathione concentrations and upregulates inducible nitric oxide synthase gene expression in intestinal epithelial cells. J.Mol. Endocrinol. , 33 (3): 797-803

Qiang, G.F., Zhang, L., Xuan, Q., Yang, X.Y., Shi, L.L., Zhang, H.A., Chen, B.N., Du, G.H.( 2010). Effect of metformin on the formation of hepatic fibrosis in type 2 diabetic rats. Yao Xue Xue Bao. ; 45(6):801-806. 
Rayssiguier, Y., Gueux, E., Nowacki, W., Rock., E., Mazur, A. (2006). High fructose consumption combined with low dietary magnesium intake may increase the incidence of the metabolic syndrome by inducing inflammation. Magnes Res., 19:237-243.

Reddy, K.J., Singh, M., Bangit, J.R., Batsell, R.R.( 2010). The role of insulin resistance in the pathogenesis of atherosclerotic cardiovascular disease: an updated review. J. Cardiovasc. Med. (Hagerstown), 11(9):633-647.

Rouru J, Huupponen R, Pesonen U, Koulu M. Subchronic treatment with metformin produces anorectic effect and reduces hyperinsulinemia in genetically obese Zucker rats. Life Sci 1992; 50: 1813-20.

Sanchez-Lozada, L.G., Mu, W.,. Roncal, C., Sautin, Y.Y., Abdelmalek, M., Reungjui, S., Le, M., Nakagawa, T., Lan, H.Y., Yu, X., Johnson, R.J.(2010). Comparison of free fructose and glucose to sucrose in the ability to cause fatty liver Eur J Nutr., 49(1): 1-9.

Shibayama, Y., Nakata, K. (1992). Role of septal fibrosis in development of hepatic circulatory disturbance in the presence of liver cell enlargement. Liver ,12:84-89.

Souza, C.G., Moreira, J.D., Siqueira, I.R., Pereira, A.G., Rieger, D.K., Souza, D.O., Souza, T.M., Portela, L.V., Perry, M.L.( 2007). Highly palatable diet consumption increases protein oxidation in rat frontal cortex and anxiety-like behavior. Life Sci.,81:198-203.

Spruss, A., Kanuri, G., Stahl, C., Bischoff, S.C., Bergheim, I. (2012). Metformin protects against the development of fructose-induced steatosis in mice: role of the intestinal barrier function. Laboratory Investigation. ; 92: $1020-1032$.

Stadelmann, C., Lassmann, H.(2000). Detection of apoptosis in tissue sections. Cell Tissue Res. ,301:19-31.

Stadler, K., Bonini, M.G., Dallas, S., Jiang, J., Radi, R., Mason, R.P., Kadiiska, M.B.(2008). Involvement of inducible nitric oxide synthase in hydroxyl radicalmediated lipid peroxidation in streptozotocin-induced diabetes. Free Radic.Biol.Med. ,45 (6) 866-874

Stanhope, K.L., Havel, P.J. ( 2008). Fructose consumption: potential mechanisms for its effects to increase visceral adiposity and induce dyslipidemia and insulin resistance. Curr. Opin. Lipidol., 19:16-24.

Stanhope KL, Havel PJ (2009). Fructose consumption: considerations for future research on its effects on adipose distribution, lipid metabolism, and insulin sensitivity in humans. J. Nutr., 139:1236S-1241S

Stanhope,K.L., Schwarz, J.M., Havel, P.J. (2013).Adverse metabolic effects of dietary fructose: results from the recent epidemiological, clinical, and mechanistic studies. Curr Opin Lipidol. , 24(3):198-206.

Suvik, A., Effendy, A.W.M. (2012). The use of modified Masson's Trichrome Staining in collagen evaluation in wound healing study. Malaysian Journal of Veterinary Research; 3: 39-47.
Takahashi, Y., Fukusato, T., Inui,A., Fujisawa, T. (2012). Pediatric nonalcoholic fatty liver disease/nonalcoholic steatohepatitis. Nihon Rinsho., 70(10):1827-1834.

Valla, D.C. (2008). Budd-Chiari syndrome and veno-occlusive disease/sinusoidal obstruction syndrome. Gut. , 57(10):1469-1478. doi: 10.1136/gut.2007.133637.

Vincent, A.M., Brownlee, M. , Russell, J.W. (2002). Oxidative stress and programmed cell death in diabetic neuropathy. Ann N Y Acad Sci. , 959:368-383.

Wang, J., Gallagher, D., DeVito, L.M., Cancino, G.I., Tsui, D., He, L., Keller, G.M., Frankland, P.W., Kaplan, D.R., Miller, F.D. (2012). Metformin activates an atypical PKC-CBP pathway to promote neurogenesis and enhance spatial memory formation," Cell Stem Cell, 11: 23-35.

Wei, T., Chen, C., Hou J., Xin, W., Mori, A. (2000). Nitric oxide induces oxidative stress and apoptosis in neuronal cells. Biochim Biophys Acta ; 1498(1):72-79.

Wei, X. Q., Charles, I. G., Smith, A., Ure, J., Feng, G.-J., Huang, F.-P., Xu, D. M., Muller, W., Moncada, S. \& Liew, F. Y. (1995). Altered immune response in mice lacking inducible nitric oxide synthase. Nature, 375: 408411.

Wei, Y., Wang, D., Pagliassotti, M.J. (2005). Fructose selectively modulates c-jun N-terminal kinase activity and insulin signaling in rat primary hepatocytes. J Nutr. ;135(7):1642-1646.

Wolf, B.B., Schuler, M., Echeverri, F., Green, D.R. (1999). Caspase-3 is the primary activator of apoptotic DNA fragmentation via DNA fragmentation factor45/inhibitor of caspase-activated DNase inactivation. J Biol Chem. ,274: 30651-30656.

Woo, M., Hakem, R., Soengas, M.S., Duncan, G.S., Shahinian, A., Kägi, D., Hakem, A., McCurrach, M., Khoo, W., Kaufman, S.A., Senaldi, G., Howard, T., Lowe, S.W., Mak, T.W.( 1998). "Essential contribution of caspase 3/CPPp32 to apoptosis and its associated nuclear changes," Genes and Development, 12, ( 6): 806-819.

Woo, S.L., Xu, H., Li, H., Zhao, Y., Hu, X., Zhao, J., Guo, X., Guo, T., Botchlett, R., Qi, T., Pei, Y., Zheng, J., Xu, Y., An, X., Chen, L., Chen, L., Li, Q., Xiao, X., Huo, Y.,Wu, C.( 2014). Metformin ameliorates hepatic steatosis and inflammation without altering adipose phenotype in diet-induced obesity. PLoS One.; 17: 9(3):e91111.

Zhang, H.F., Shi, L.J., Song, G.Y., Cai, Z.G., Wang, C., An, R.J.(2013). Protective effects of matrine against progression of high-fructose diet-induced steatohepatitis by enhancing antioxidant and anti-inflammatory defences involving Nrf2 translocation. Food Chem Toxicol., 55:7077. doi: 10.1016/j.fct.2012.12.043.

Zhang, X., Barile, G., Chang, S., Hays, A., Pachydaki, S., Schiff, W., Sparrow, J.(2005) "Apoptosis and cell proliferation in proliferative retinal 
disorders: PCNA, Ki-67, caspase-3, and PARP expression," Current Eye Research, 30, (5):395-403.

Zhang, X., Dong, F., Ren, J., Driscoll, M.J., Culver, B. (2005). High dietary fat induces NADPH oxidaseassociated oxidative stress and inflammation in rat cerebral cortex. Exp. Neurol., 191:318-325.

Zhao, C.H., Liu, H.Q., Cao, R., Ji, A.L., Zhang, L., Wang, F., Yang, R.H. (2012). Effects of dietary fish oil on learning function and apoptosis of hippocampal pyramidal neurons in streptozotocin-diabetic rats. Brain Res., 1457:33-43.
Zheng, R.Q., Wang, Q.H., Lu, M.D., Xie, S.B., Ren, J., Su, Z.Z., Cai, Y.K., Yao, J.L.(2003). Liver fibrosis in chronic viral hepatitis: an ultrasonographic study. World J Gastroenterol., 9(11):2484-2489.

Zochodne, D.W., Levy, D. (2005). Nitric oxide in damage, disease and repair of the peripheral nervous system. Cell Mol Biol (Noisy-le-grand). , 51(3):255-267. 